This item was submitted to Loughborough's Research Repository by the author.

Items in Figshare are protected by copyright, with all rights reserved, unless otherwise indicated.

\title{
From fail to first: revising assessment criteria in art and design
}

PLEASE CITE THE PUBLISHED VERSION

http://dx.doi.org/10.1386/adch.10.1.67_1

PUBLISHER

(c) Intellect

VERSION

AM (Accepted Manuscript)

LICENCE

CC BY-NC-ND 4.0

REPOSITORY RECORD

Harland, Robert G., and Phil Sawdon. 2019. "From Fail to First: Revising Assessment Criteria in Art and Design". figshare. https://hdl.handle.net/2134/9735. 
This item was submitted to Loughborough's Institutional Repository (https://dspace.lboro.ac.uk/) by the author and is made available under the following Creative Commons Licence conditions.

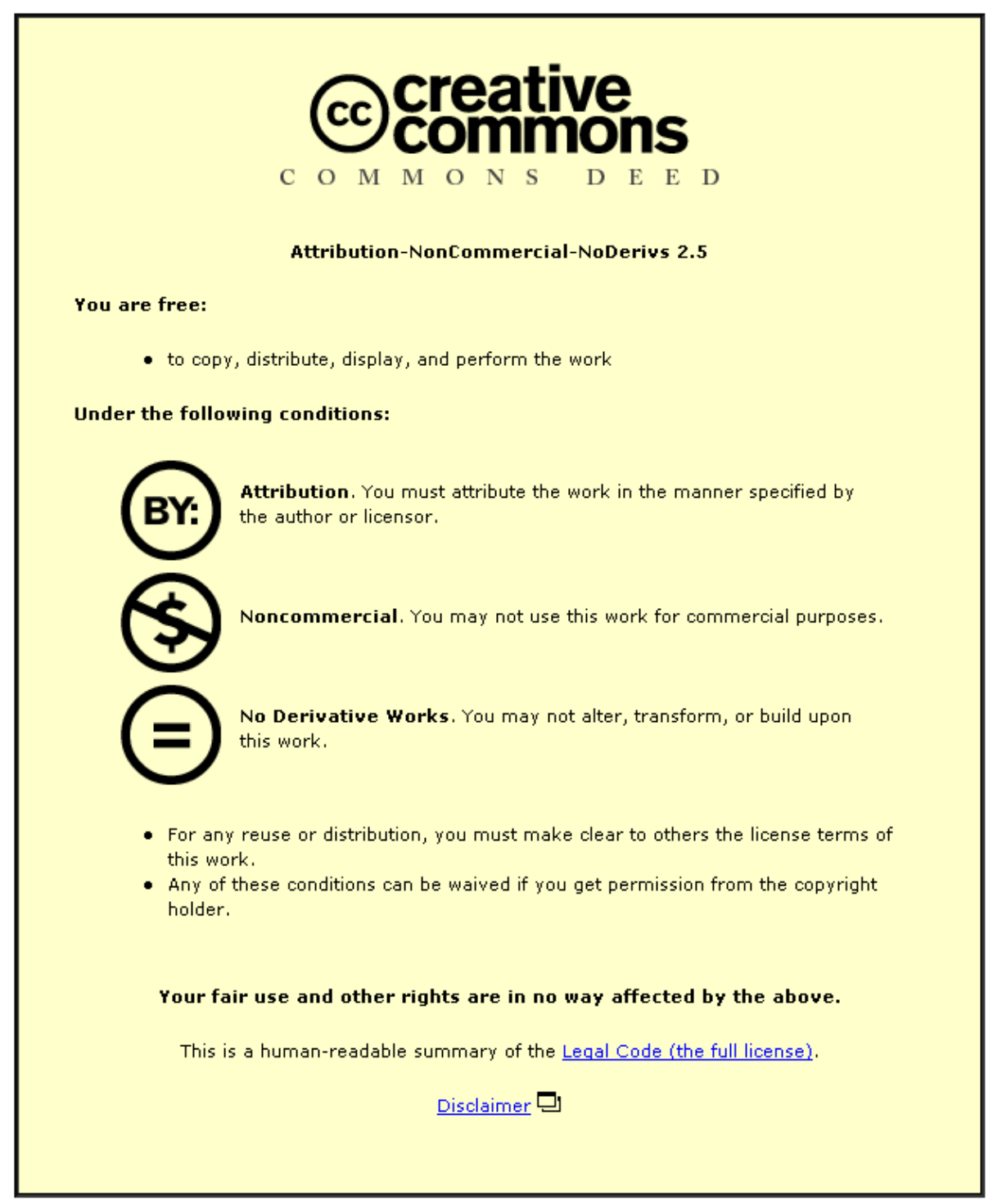

For the full text of this licence, please go to: http://creativecommons.org/licenses/by-nc-nd/2.5/ 
The following text is the 'accepted for publication (author final)' version of an article published in the journal Art, Design \& Communication in Higher Education, April 2012

The definitive article citation (as recommended by the journal) and location is as follows:

Harland, R. and Sawdon P. (2012), 'From fail to first: Revising assessment criteria in art and design', Art, Design \& Communication in Higher Education 10: 1, pp. 67-88, doi: 10.1386/adch.10.1.67_1

www.intellectbooks.co.uk/journals/view-Article, $i d=12799 /$

If citing from this 'author final' version, please refer to the journal page numbers that have been inserted in square brackets within this text, for example [...]. These reflect the final published version. 


\title{
From fail to first: Revising assessment criteria in art and design
}

Robert Harland and Phil Sawdon, Loughborough University

\begin{abstract}
This article serves two purposes. First, it explains a review and development process for revising the application of assessment criteria for undergraduate art and design students in the United Kingdom. Second, it makes data generated by the process available for use by others. These data consist of keywords used to locate student learning across the numerical scale of marking typically employed in higher education art and design assessment procedures, and six different ways that this numerical scale has been used. Additionally, student participation in the development process is explained. Discussion about the process acknowledges the emergence of learning, meaning and identity in a social theory of learning, and the importance of assessment literacy in the development of pedagogical intelligence. The article will be of interest to those concerned with the development of assessment criteria in art and design, and how this might be improved through consistent use and formatting of criteria for use in formative and summative feedback mechanisms.
\end{abstract}

\section{Keywords}

assessment criteria

feedback

keywords

critical pedagogy

marking bands

alignment

[end page 67] [start page 68]

\section{Introduction}

In recent years there has been an emerging interest in art, design and media higher education assessment practices in the United Kingdom. Blair (2006) has concentrated on the learning value of the large studio crit, Malins (2007) has investigated assessment practices in relation to personal development planning, Sober (2009) and Matthews (2009) consider team working and peer assessment, and Orr has been concerned with assessment practices in art and design (2006), particularly art and design lecturers (2010) in relation to judgement making and feedback processes (2011). Further afield in Australia, Cowdroy and Williams (2006) have discussed problems associated with assessing creativity in relation to quality assurance. Furthermore, The Higher Education Academy Art Design Media Subject Centre hosted the two-day symposium 'A Space for Assessment' at Kingston University London in 2010. Aside from a presentation at that symposium about newly developed marking criteria for undergraduate and postgraduate students at the University of the Arts London, given by Shân Wareing (2010), little appears to have been reported about how assessment criteria, and their application, are developed.

This article reports on a pre-implementation study in the School of the Arts $^{1}$ at Loughborough University as part of an ongoing critical review and development process revising published information for undergraduate students about the application of assessment criteria. This covers two kinds of module usually studied by art and design 
students in the United Kingdom, referred to here as 'studio' and 'contextual studies' modules. The former concentrates on making artefacts, the latter consists of written work. $^{2}$ The critical review and development process has been undertaken by a working group of six academic staff ${ }^{3}$ representing the School's core subjects in Fine Art, Visual Communication, ${ }^{4}$ Textiles and Three-Dimensional Design.

The project extends a revision of assessment criteria across four principle areas: knowledge and understanding, subject-specific cognitive skills, subject-specific practical skills and key/transferable skills. This responded to internal quality assurance requirements, National Student Survey (NSS) feedback and a desire to refine, reduce and avoid replication that had arisen as a consequence of incremental and individual edits without sufficient reference to the overall criteria statements. The review also represented a direct response to feedback from external examiners who over time questioned why the full range of percentage grades is underutilized, especially at the high and low levels. Those undertaking this review recognize this in the similar roles they perform elsewhere.

The purpose of this article is to share with the wider academic community the experience, observations and findings that the development process revealed, and initial feedback from those who have a vested interest in the practice of giving and receiving formative and summative assessment. The work took place during the early part of the 2009-2010 academic year in time for implementation in the student handbook for the 2010-2011 intake. In summary, the article reports on: the need to revise assessment criteria and the approach taken; a review of language used across the sector to substantiate grade indicators; the adoption here of a keyword strategy to help structure criteria for the benefit of staff and students; the integration of keywords into revised and/or rewritten band descriptors; the student consultation process; and initial feedback about the revised criteria. [end page 68] [start page 69]

\section{The need to revise the application of assessment criteria}

Recent literature suggests that reviewing assessment and feedback practice with any aspiration towards a more holistic approach will be a challenging and convoluted process. The complexity associated with this was relatively unknown to the working group. Nevertheless, there were three reasons for revising the text to explain the application of assessment criteria.

- To enhance assessment and feedback between academic staff and undergraduate students by improving how staff produce and students interpret written feedback.

- To identify language use that may be commonly understood across staff marking teams and be meaningful to staff and students alike in a shared dialogue that more accurately represented student achievement.

- To continue to develop the quality and clarity of module formative and summative assessment feedback when mapped against individual module-intended learning outcomes.

These reasons collectively reveal an intent to develop clear support and guidance for staff and students by enhancing what Price et al. refer to as 'assessment literacy' (2011: 490). They argue that the conditions for achieving this depends on an intricate network of ten key premises susceptible to assumed and real practices. These key premises acknowledge that: 
- Assessment is central to the student learning experience.

- Assessment must focus on learning rather than on marking and measurement.

- A key reason for assessment failing to support learning is ineffective feedback.

- Assessment is complex.

- Assessment of high-level and complex learning is under threat.

- Assessment standards are under threat.

- Assessment standards reside in academic/professional communities.

- Learning is more effective when students understand the assessment process.

- 'Over-assessment' is a meaningless term.

- How the assessment environment is managed impacts strongly on the effectiveness of assessment. (Price et al. 2011: 480-89)

A meaningful assessment strategy and policy collectively conscious of these is said to be determined by institutional priorities balanced between a set of continuums: simplicity complexity; measurement - learning; individual - community; efficiency - effectiveness; quality assurance - enhancement (Price et al. 2011: 489). These consider the range of assessment, balance between formative and summative process, individual or team scenarios (staff and student), human resources, and accountability. This complicated range of considerations contrasts with the modest intention behind this attempt to revise assessment criteria. In short, the suitability of existing word usage (e.g. 'original', 'creative', 'sound', 'strong', 'poor', 'minimal', 'competent', 'moderate' and 'limited') was in need of a critical review. This prompted some basic questions. What do such words mean to staff and students? Is there more appropriate terminology? How might such words match incremental percentage grade [end page 69] [start page 70] bands? How does this help staff and students build cohesive understanding that appropriately supports student learning in art and design?

This article attempts to demonstrate how these questions were addressed. It responds to a perceived need to change student learning by changing methods of assessment (Brown 1997: 7) through enhanced understanding of assessment criteria. In doing so, the authors acknowledge Paul Ramsden's view that 'assessment always involves making fallible human judgements... made by students and teachers about progress all the time' (2003: 181). Generally these judgements are expressed and exchanged through verbal, and increasingly, written language in ways that Ramsden suggests is not 'right or wrong' but 'human and uncertain'. His use of right or wrong reflects a high degree of objectivity, but it is clear that human evaluation, as part of assessment, is not impartial and vulnerable to subjectivity, one of the underlying themes in the work of Etienne Wenger (1998) on learning, meaning and identity.

The development process explained here is about refining what Wenger calls the 'interweaving of production and adoption of meaning' (1998: 188-213) through shared participation. Although unfamiliar to the working group at the time, a desire to explore a common use of language fits with his belief in the importance of 'identification and negotiability' in the configuration of identity. Wenger argues for the importance of identity as part of a social theory of learning that has four components: 
Meaning: a way of talking about our (changing) ability - individually and collectively - to experience our life and the world as meaningful.

Practice: a way of talking about the shared historical and social resources, frameworks, and perspectives that can sustain mutual engagement in action.

Community: a way of talking about the social configurations in which our enterprises are defined as worth pursuing and our participation is recognizable as competence.

Identity: a way of talking about how learning changes who we are and creates personal histories of becoming in the context of our communities. (1998: 5)

With this in mind, a focus on the language of assessment criteria here contributes to the growing importance and urgency of research into assessment and feedback in the United Kingdom (Price et al. 2011: 479). This follows on and is further emphasized by students who are said to welcome attempts to use 'criterion referenced assessment tools and processes' (Rust et al. 2003: 151) to explicate the meaning of terms and phrases in the often inconsistent relationship between criteria and feedback. They suggest that the development of tools does not necessarily lead to a shared understanding between staff and students, recognizing this having further developed and tested common criteria assessment grids in undergraduate Business Studies at Oxford Brookes University (following initial work in the late 1990s). However, they also note real benefits of such a tool that could lead to greater consistency in marking between staff, provide students with clear guidance and help directing markers to be more specific in their feedback (Rust et al. 2003: 149). This last point reinforces the importance of good communication to help the student understand their level of achievement. [end page 70] [start page 71]

Similar reviews of assessment criteria in art and design have previously taken place across the sector. For example, this project happened at the same time as a much larger four-year initiative at the University of the Arts London, reported at the earlier mentioned symposium (Wareing 2010). The results from this contributed one of the nine data sets reviewed in this research. That project identified the eight benefits to reification in assessment practices that use fixed criteria. The context for Wareing's work is institutionally different from the project reported in this article, but the issues identified by her relating to inducting staff, consistency of marking, pedagogic principles, the full spectrum of student outputs, feedback for improvement, social and cultural difference, personal prejudice and written feedback are relevant to most modern higher education settings in the United Kingdom, including Loughborough University. It is hoped that the process described here offers a helpful insight and model if others choose to seek consolidation or diversification in the application of assessment criteria practices.

\section{Approach}

Situating the rewriting of the application of assessment criteria in a research context, the process utilized aspects of 'content analysis' and 'focus group' research (two established research methods), as well as what has been called 'graphical method' in 'practice-based research' (Biggs and Buchler 2008: 5-18). Content analysis is referred to here in a much simplified form than as a quantitative method for analysing the frequency of word usage 
in a text (Denscombe 2007: 236-38). Focus group activity provided quick feedback on the level of agreement (Denscombe 2007: 180) about the ranking of keywords. This was facilitated in an interactive and informed manner with several participants (Bryman 2008: 474). The less familiar technique of graphical method will be seen to have played a significant part in testing a revised format for the presentation of the application of assessment criteria in what has been classified by Alan Bryman as 'research-driven' visual data (2008: 424). This involved the standard design and formatting of text into a matrix, and the importance of this approach is that design process was actively undertaken as part of the review process, and as a research-driven exercise.

\section{The initial development process}

The first task reviewed how other higher education institutions explained their criteria for assessment. Nine different institutional assessment criteria data sets were selected from sources directly available to them as former employees, external examiners or subject reviewers. These were drawn from the Arts Institute at Bournemouth (now the Arts University College at Bournemouth), Bath Spa University, University of Bath, University of Derby, University of Hertfordshire, Portsmouth University, Nottingham Trent University, University of the Arts London and Loughborough University. Initial analysis revealed six different models for dividing assessment bands between 0 and 100 per cent. These ranged from as few as five to the most detailed of nineteen percentage divisions. Table 1 shows the diversity of assessment criteria percentage bands in six distinct variations extracted from the sample of nine data sets. [end page 71] [start page 72] 


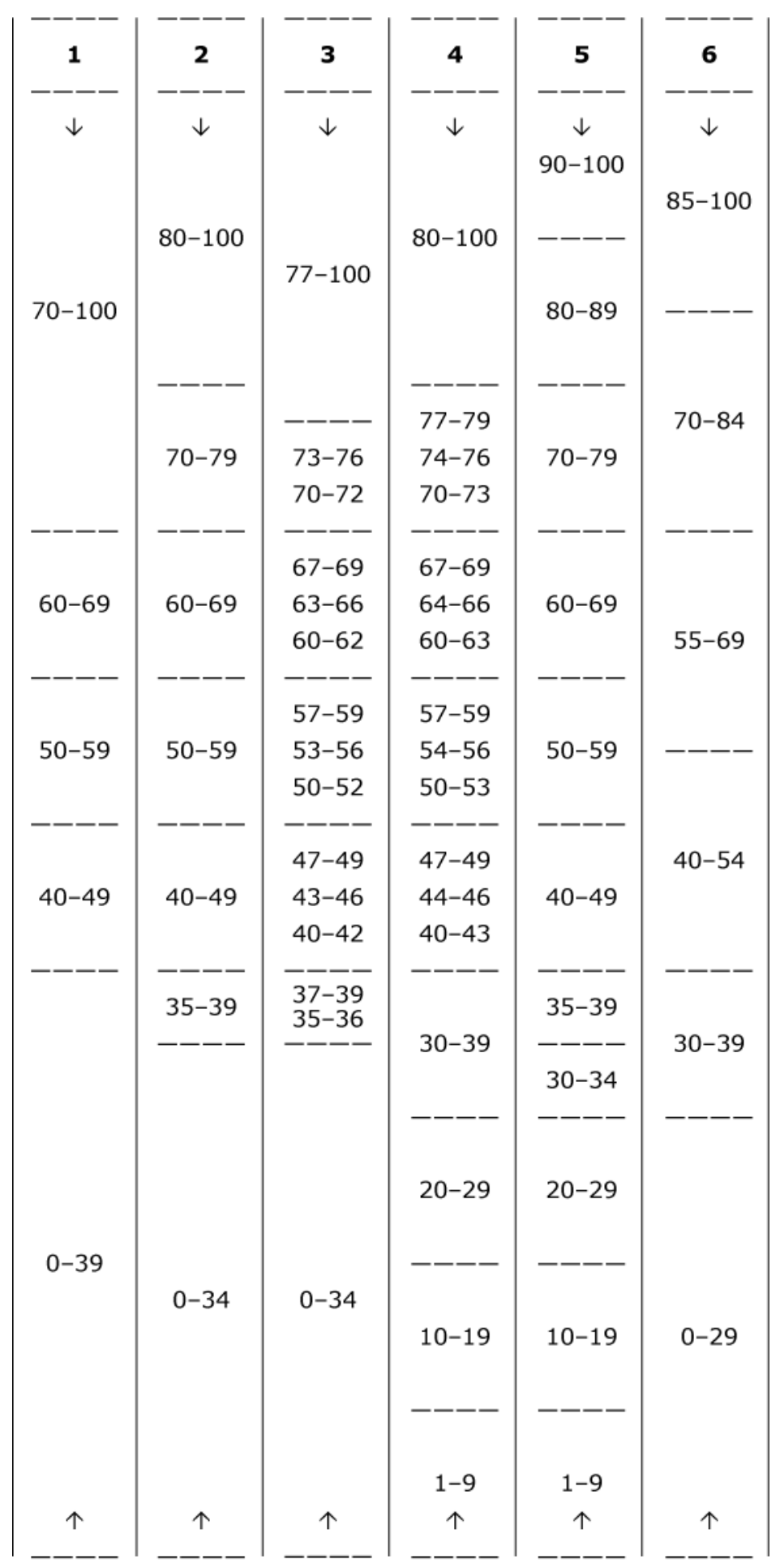

Table 1: Six models for organizing assessment criteria across percentage bands.

[end page 72] [start page 73]

All six models conform to a fail-pass threshold of $40 \%$, and the majority with the sector norm that determines a fail (0-39\%), third-class (40-49\%), lower-second class (50$59 \%$ ), upper-second class (60-69\%) and first-class (70-100\%) degree. Most conform to a 
multiple of ten - whereas some include percentage divisions within a unit of ten (see three and four). Model six is distinct in that it utilizes irregular bands.

After reviewing these, the working group adopted model five with the slight adjustment of treating the 30-39 band as a single unit, for the purpose of establishing keyword criteria. This appealed on the basis that it was a reasonable and equitable division of the full range of marks. It was also the intention to extend the range of marking to the higher and lower levels, especially when marking across a number of key learning outcomes. This established a framework for developing the next phase of work, the objective being to identify a set of keywords that could indicate levels of achievement for each 10 per cent band.

A similar exercise had previously been developed in the School but relating to Part C (Year 3) dissertation marking only. That scheme argued for highly detailed description for levels of achievement and used an average 60-65 words. This was thought to be useful for internal classification and marking but did not fit the purpose here. It appears uninviting for students to read and understand, therefore being unwieldy as a tool for collective use by staff and students alike.

As part of the review of nine data sets, the working group set about compiling a set of key terms and gradually composed these into a matrix as shown in Table 2 . This provided a sample of terms used across the sector and their respective location in relation to grade bands. Some anomalies were found, such as the duplication of some words across two bands within the same data set (e.g. sound) as well as the variable placement of some words (e.g. excellent, good, sound, satisfactory, poor). In particular, the word 'excellent' is used by two organizations that are 20 per cent apart. One institution also combined their criteria with a letter grade (shown in the table).

Reviewing the matrix provided an invaluable resource for linking discussion between studio and contextual studies module staff, as it was possible to then consider various words in both situations. Some were thought to be more suitable for one or another, whereas many applied to both. Equally, some words tested the ability to interpret meaning in an unfamiliar situation. In this article, it is difficult to capture the subtlety and nuance of discussion between the members of the working group, but the process encouraged and extended not only debate across module kind, programme area and what the constitution of a subject, field or discipline might be. For example, the use of the word 'objective' had different connotations for Fine Art staff when compared to how it may be utilized in Art History.

Through a series of meetings, each 10 per cent band category was then carefully discussed until a set of keywords emerged that could be used to carry the process through to the next stage of rewriting the application of assessment criteria. As a starting point, words were proposed by each member of the working group, as well as being extracted from the keyword matrix. When inadequacies remained and the group did not agree, new words were sourced (using dictionaries and thesauruses), shared and, if unanimously agreed added to the list. For example, 'autonomous' was suggested and agreed but 'reification' rejected. Some refinement also happened for existing words such as 'reasonable', it being changed to the [end page 73] [start page 74] 


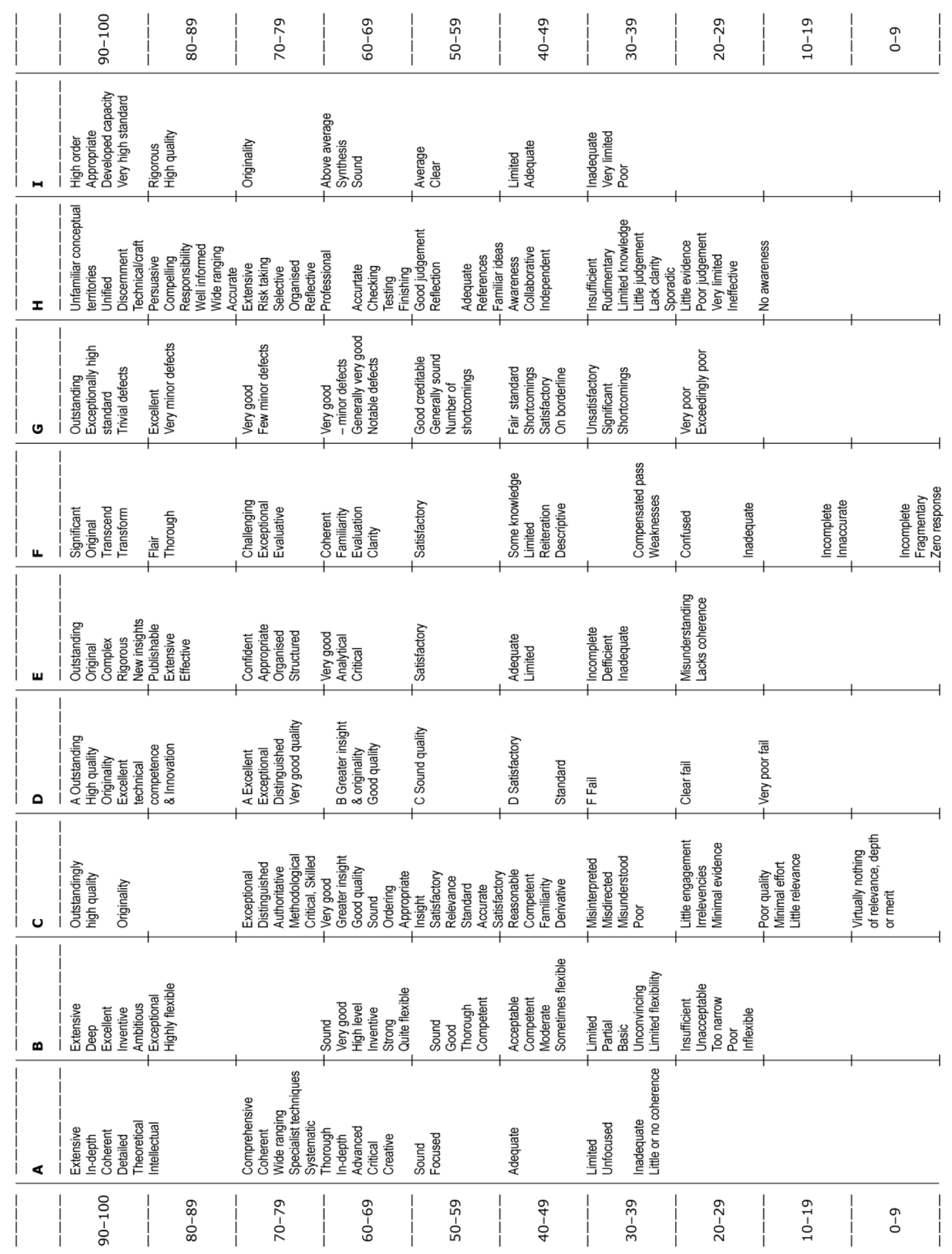

Table 2: Assessment criteria keyword analysis from nine higher education establishments. 


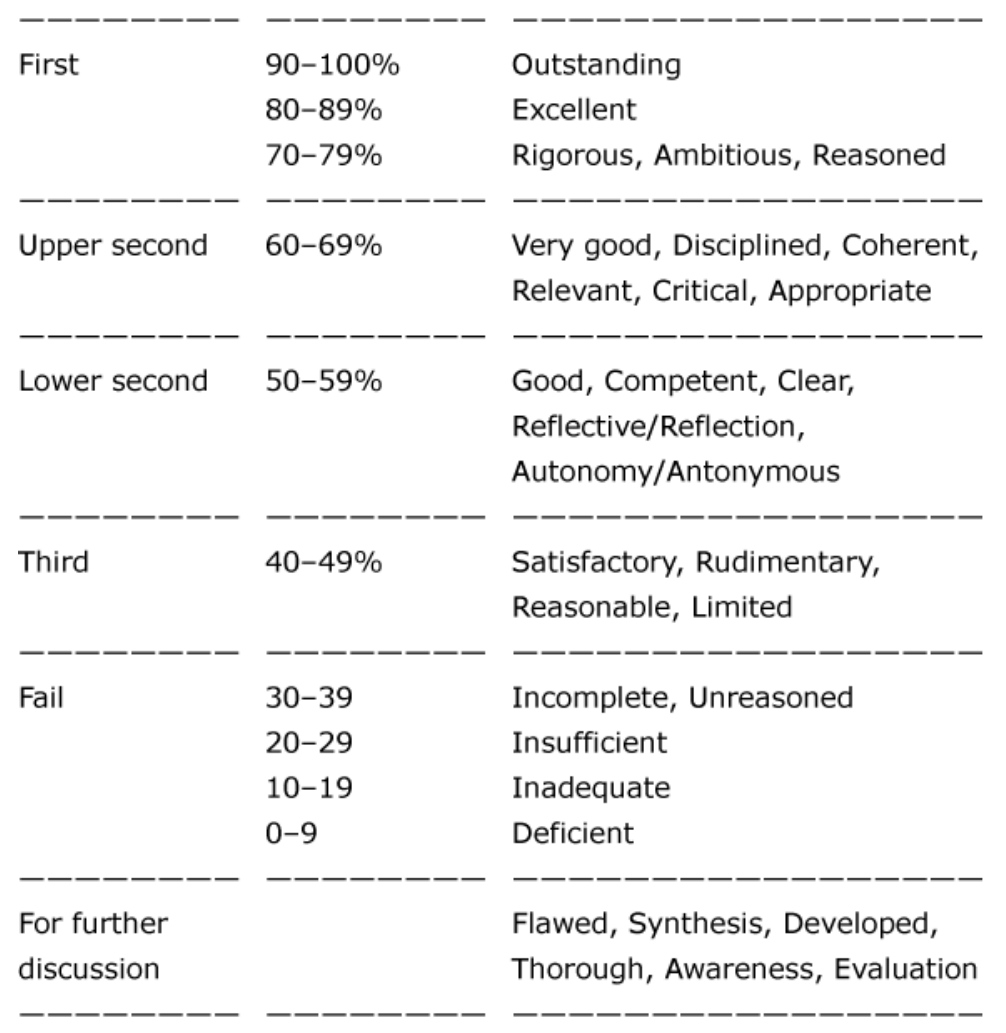

Table 3: Establishing a keyword set for writing the application of assessment criteria.

more demonstrable 'reasoned'. Some words were thought to be inappropriately located and were repositioned. For example, 'rigorous' was thought to be a quality that should be evident in the higher levels of attainment, but not as high as suggested by its position in the 90-100 band as indicated in one data set. 'Rigour' was thought to be essential for a first-class degree and a student could achieve a first by demonstrating rigorous process, but the work may not reach a level of excellence, or be outstanding. This usefully began to suggest differentiation between a low- and high-first class degree - the higher levels of achievement obviously incorporating rigour. Additional sources also revealed that 'rigour' was also noted as having the appeal of being a keyword in the forthcoming Research Excellence Framework (REF) (HEFCE 2011: 6). 'Originality, significance and rigour' form the basis of 65 per cent of the REF assessment criteria.

For the purpose of enabling the rewriting of assessment criteria to begin, an initial set of agreed words were listed against appropriate classification bands, as shown in Table 3. Some bands contained one word only whereas others where the majority of marks are awarded utilized several. Some words were highly favoured, such as 'flawless'. However, this term did not have unanimous acceptance across the working group and was retained for further discussion during the writing process. Others were also held in reserve such as 'synthesis', 'developed', 'thorough', 'awareness' and 'evaluation'. [end page 75] [start page 76] 


\section{Moving beyond the initial keyword stage}

Once a draft set of keywords had been established further questions arose: how should they be used, tested and integrated? Two possible approaches were considered:

- Seek student feedback on keywords, before writing assessment criteria bands.

- Write the keywords into assessment criteria bands, and then seek student feedback.

The working group adopted the second of these approaches on the basis that this would allow some testing of the keywords in context and allow time for refinement and clarification in situ, especially where word variations existed (e.g. reflective/reflection, autonomy/autonomous). This was thought to be more compatible with an early recognition for students to be part of the development process, and could be planned into the next phase of work. Wenger will recognize this as an attempt to build a community of practice through three distinct modes of belonging that include 'engagement', 'imagination' and 'alignment' (1998: 171-87). These will not be discussed here, except to foreground the importance of alignment in bringing together different perspectives, negotiating shared meaning, fulfilling responsibility, unification, explaining flexible procedure and reconciliation.

Band descriptors were written against the four principle areas mentioned earlier in a series of four working group meetings and included all group members. The primary objective of the meetings was to review existing text and draft keywords into revised reduced statements on a band-by-band basis. This approach was preferred to staff assuming individual responsibility for one band, rewriting and then reconvening to share the outcome - it was felt this carried too much risk of stylistic variation. Once this had been done, the intention was to discuss with a student focus group for initial feedback. Before explaining the focus group activity, it is worth noting some observations about the writing process for the band descriptors.

\section{Integrating keywords with assessment criteria text}

Two significant issues remained paramount in the process of drafting band descriptors: (1) the decision to make clear the assessment criteria for each 10 per cent band and (2) the need to enhance understanding through the use of clear language between three key user groups: staff-to-staff, staff- to-student and student-to-student. Here again Wenger's work on alignment is emphasized in terms of reification. He argues that 'alignment requires sharable artifacts [sic] - boundary objects able to create fixed points around which to coordinate activities' (1998: 187). The establishment of keywords became the boundary objects. Also, the working group agreed that the previous descriptors were too long and would benefit from considerable reduction, making them more inviting for staff and students to read and for use as a teaching aid.

Early discussion focused on some key questions: how to differentiate between the bands in the $70-100 \%$ and $0-39 \%$ bracket? How do the keywords find their way into the criteria descriptions in a meaningful way? How should they be used? For example, a list of possible words for the 50-59\% bracket read: good, competent, reflective, clear, autonomous. However, what do these [end page 76] [start page 77] mean to staff and students? What is the student good at... competent in... clear about...? The Quality Assurance Agency (QAA) honours degree subject benchmark statements and qualification descriptors in the framework for higher education qualifications (QAA 
2008) state that students are expected to undertake projects and make judgements about their learning. Assessment and feedback is part of this and guidance on assessment of students declares that the language of study and assessment 'used in teaching and assessment are normally the same' (QAA 2006: 32).

Not surprisingly, what emerged from the exercise is that some keywords fitted better than others to the different bands, but this revealed that relative position in a matrix played an important role in shaping the meaning of a keyword. Also, the keywords for the 60-69 per cent grade band were more easily fitted to the task of contextualization. The initial keywords for this band - very good, disciplined, coherent, relevant, critical and appropriate - could be worked into a paragraph by reordering and pairing up word combinations. At the other end of the scale an important realization was that the $0-39$ per cent band - almost half of the total mark available in any given task - represented the largest section of the grading spectrum, but was least used.

Degree classification in UK higher education art and design typically line-up with five uneven divisions across the 100 per cent scale:

$70-100 \% \quad$ First class honours (1st)

60-69\% Second class honours, upper division (2.1)

50-59\% Second class honours, lower division (2.2)

40-49\% Third class honours (3rd)

0-39\% Fail

A student may fail across a percentage band that is a third larger than the collective thirdclass, second-class (lower) and second-class (upper) bands. Yet these higher bands take in the majority of all degree classifications (experience also suggests the vast majority of first class degrees are awarded in the 70-79 per cent band).

This current system poses the important question: how should the percentage grades be described that fall below the $40 \%$ threshold? An initial collection of keywords below the $40 \%$ threshold - 'limited', 'insufficient', 'very limited' and 'devoid' - alluded to some sort of descending priority. However, closer inspection revealed too much ambiguity here. Limited, for example, might (and often does) describe work in the $40-49 \%$ band. Work may be limited, but there might be enough to pass! $!^{5}$ The challenge of determining four levels of failure proved difficult but this was helped by emphasizing the adjacency of $30-39 \%$ band to pass threshold of $40 \%$. The pass threshold is the 'limit'. More relevant terms for this were debated that focused on a 'near miss' scenario (such as 'marginal') or at least suggest a level of achievement very close to the pass threshold. This seemed an important issue in terms of placing a positive stance on a fail that is so close to a pass.

The following terms were discussed as better fitting the four fail bands that reside between 0 and 39 per cent:

30-39: boundary, peripheral, marginal, fringe, contiguous, subsidiary, tangential, marginal, ancillary, negligible, diminished, moderate, constricted; [end page 77] [start page 78]

20-29: limited: insubstantial, short-supply, meagre, deficient, sparse, minimal; 
10-19: insufficient: poor, scant, not enough, too little, sparse, wanting, incomplete;

1-9: devoid: empty, vacant, bereft, deprived, destitute.

A sample comparison of old and revised assessment criteria for high and low levels of achievement is shown in Table 4. The revised is extracted from an early draft of the application of assessment criteria. The old text made little attempt to help staff or students determine the difference between, say, 73 or 93 per cent. This can/might be construed as therefore encouraging a certain amount of speculation between staff and students about the meaning associated with different levels of a first, and whether terminology can reasonably reflect a low or high first.

\section{Knowledge and understanding}

Old assessment criteria
$\mathbf{7 0 - 1 0 0 \%}$ The coursework in this range will
demonstrate awareness of a high order, based
on knowledge and understanding of appropriate
contexts (historical, theoretical, cultural, social,
industrial and material) and a developed capacity
for the acquisition, evaluation and use of
information and knowledge. The coursework will
demonstrate a very high standard of sustained
endeavour, evidence of assimilation and
understanding, and the incorporation of primary
sources, where appropriate.

$\mathbf{0 - 3 9} \%$ The coursework will demonstrate a level of awareness based on very limited knowledge and understanding of appropriate contexts and little ability to acquire evaluate and use information and knowledge. The coursework will be poor with serious omissions and misconceptions.

\author{
Revised assessment criteria (first draft) \\ The submission demonstrates through the work \\ and its presentation: \\ $\mathbf{9 0 - 1 0 0 \% ~ o u t s t a n d i n g ~ i n s i g h t , ~}$ \\ knowledge and understanding, with reasoned \\ interpretation of the subject, field and discipline. \\ $\mathbf{8 0 - 8 9 \%}$ excellent insight, ambition, knowledge \\ and understanding, with reasoned interpretation \\ of the subject, field and discipline.

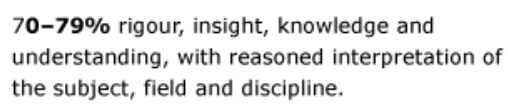 \\ The submission demonstrates through the work \\ and its presentation: \\ 30-39\% marginal knowledge and understanding \\ that is less than satisfactory, inadequate, and \\ unreasoned. \\ 20-29\% insubstantial knowledge and understanding \\ that is unsatisfactory, inadequate, and lack reasoning. \\ $\mathbf{1 0 - 1 9 \%}$ insufficient knowledge and understanding \\ that is unsatisfactory, inadequate, and lack reasoning. \\ 0-9\% deficient knowledge and understanding that \\ is unsatisfactory, inadequate, and lacks reasoning.
}

Table 4: Sample comparison for old and new assessment criteria.

[end page 78] [start page 79]

\section{Student consultation}

Once an initial set of keywords had been established, attention turned towards the student consultation process. Nine people took part in a focus group meeting including five student representatives, three members of the working group, plus one additional member of staff unfamiliar with the project. Overall this constituted representation from each of the four core subject areas in the school. Before the criteria statements were discussed, a 
short activity took place designed to encourage student involvement. Those present were asked to look at a random arrangement of ten keywords that had emerged during the early writing process, and rank them between 1 (low) and 10 (high) for levels of achievement (see Figure 1).

\section{Establishing some keywords}

A short exercise: number the words in order of achievement

1 = low

$10=$ high

\section{deficient}

good

insubstantial

marginal

outstanding satisfactory

insufficient

very good

rigorous

excellent

Figure 1: Random keywords for assessment ranking.

The aim of this was to see if the focus group ranking matched that of the working group single keyword recommendations as they had developed through the writing of the application of assessment criteria statements. These were as follows:

90-100\% outstanding

80-89\% excellent

$70-79 \%$ rigorous

60-69\% very good

$50-59 \%$ good

$40-49 \% \quad$ satisfactory

$30-39 \%$ marginal

$20-29 \%$ insufficient

$10-19 \%$ insubstantial

0-9\% deficient

[end page 79] [start page 80] 
The staff member unfamiliar with the project also agreed to take part in the process. The outcome of this impromptu task from four student participants (one student chose not to submit their response) and one staff member is shown in Table 5. Overall, this small sample indicated that the focus group ranking of key terms were well matched with the working group recommendations. There was some minor variation between the respective level for 'insubstantial' and 'marginal', and 'deficient' and 'insufficient', but this represented a variation thought to be within a reasonable tolerance.

$\begin{array}{lllll}\text { staff } & \text { student 1 } & \text { student 2 } & \text { student 3 } & \text { student 4 } \\ \text { outstanding } & \text { outstanding } & \text { outstanding } & \text { outstanding } & \text { outstanding } \\ \text { excellent } & \text { excellent } & \text { excellent } & \text { excellent } & \text { rigorous } \\ \text { rigorous } & \text { rigorous } & \text { rigorous } & \text { rigorous } & \text { excellent } \\ \text { very good } & \text { very good } & \text { very good } & \text { very good } & \text { very good } \\ \text { good } & \text { good } & \text { good } & \text { good } & \text { good } \\ \text { satisfactory } & \text { satisfactory } & \text { satisfactory } & \text { satisfactory } & \text { satisfactory } \\ \text { marginal } & \text { insubstantial } & \text { marginal } & \text { marginal } & \text { marginal } \\ \text { insubstantial } & \text { marginal } & \text { insubstantial } & \text { insubstantial } & \text { insubstantial } \\ \text { insufficient } & \text { insufficient } & \text { insufficient } & \text { insufficient } & \text { deficient } \\ \text { deficient } & \text { deficient } & \text { deficient } & \text { deficient } & \text { insufficient }\end{array}$

Table 5: Keyword rankings by focus group.

This revealed the need to consider the assessment criteria bands from a holistic perspective that included the way keywords were ranked in a list. There seemed to be an important 'spatial' dimension to the relationship of keywords to each other, something that could be easily overlooked when concentrating too much on the meaning of individual words. Here, we use the word spatial in relation to a thinking process that appeared to assist art and design students to rank terms in a comparative order. ${ }^{6}$ For example, 'satisfactory' was considered better than 'marginal', or 'rigorous' better than 'very good'. In simple terms, the value associated with one word is considered higher than the other, and this is evidenced in the outcome of the exercise undertaken in the focus group. Clearly, the meaning of all keywords is relative and open to interpretation, but there appears to be an accepted level of association in other simpler models. For example, when assessing written essays, the word 'marginal' determines a pass lower than the level of a third-class degree (Brown 1997: 74) in the grade/language correlation:

$1 \quad$ excellent

$2.1 \quad$ very good

2.2 good

3 moderate

$\mathrm{P} \quad$ marginal pass

F fail

Further focus group discussion happened concerning the term 'rigour' and this needed more contemplation. It was generally thought this had been the most difficult to locate, perhaps because it resembled less a level of achievement and more a quality in the work. The working group members present [end page 80] [start page 81] argued about the uses of 'rigour' in relation to methodology and methods, and requested if the focus group participants had any alternative ideas. One response from a student was that perhaps a word more resembling 'successful' could be used but subsequent discussion argued in 
favour of keeping the term rigour. Discussion then turned towards how the descriptors had been restructured, focusing specifically on the 0-39 per cent and 70-79 per cent bands. All agreed that the specific revisions were more readable, clearer to understand and helpful to the student wishing to monitor their own performance. One student suggested that this encouraged students to reflect on the accuracy of feedback and set their targets moving forward.

The meeting then turned towards the assessment criteria statements. Some concern was initially expressed by students about the word 'ambitious' in the $80-89 \%$ band, and the location of 'excellent' in the same level. The perception was that elevation of the word excellent appeared to demean student achievement in the 70-79\% band. It was explained that this had been discussed at length by the working group, but a conscious effort had been made to position terminology that encouraged a wider use of the $70-100 \%$ band, and in particular that 'excellence' should be associated with the top $20 \%$ of achievement in the view of the working group.

The staff member of the focus group questioned the use of 'marginal' in that it could be either a pass or fail. All agreed, but it was explained that most terms will have a 2-3 per cent tolerance above or below a band threshold. In general, it was thought acceptable and with hindsight fits within the same region of student achievement discussed earlier in the work of Brown (1997). Other matters included debate about the term 'deficient' between the $0-10$ per cent band, it was generally agreed to be more appropriate than 'devoid'. Finally, students were asked if any of the keywords were inappropriate. If so, could they offer any alternative suggestions? Informal comments were that a word that represented 'success' could be introduced and that 'marginal' might be replaced with 'below the threshold'. Notwithstanding, students agreed the keywords were appropriate.

Students were then presented with the revised statements for assessment criteria composed in a matrix as a double-page spread, for comparison to what had previously been formatted as running text within the 'paragraphs' of the student handbook. See Figure 2 indicating the previous formatting of assessment criteria across two double-page spreads.

In the revised format, each description clearly displayed the keyword in bold to help the student orientate horizontally and vertically across the table, as well as acting as a visual starting point for each descriptor within the matrix. It was generally thought to be much improved and more accessible than before, and inviting to read. This provided useful feedback on the template. The current text that followed this layout is shown in Figure 3. (This explains the earlier mentioned use of 'graphical method' as a proactive tool in the process.)

The intention of the focus group had been to test the keywords and initial criteria statements through student participation. This encouraged an approach to generating 'content' and 'artefacts' [sic] in order to promote participation in a 'community of [assessment] practice'. In the case discussed here, the assessment criteria matrix is the artefact that Lave and Wenger might refer to as performing a 'mediating function' through 'cultural practice and social organization' (1999: 26). This demonstrates a reflexive approach to 'shaping' the artefact. Some further editing of text happened after the student consultation to make the descriptors more explicit, inclusive of other 
keywords, more [end page 81] [start page 82] balanced in the number of words per descriptor, and to remove unnecessary duplication. A sample is shown in Table 6, the combination of 'outstanding' and 'exceptional' being a case in point.

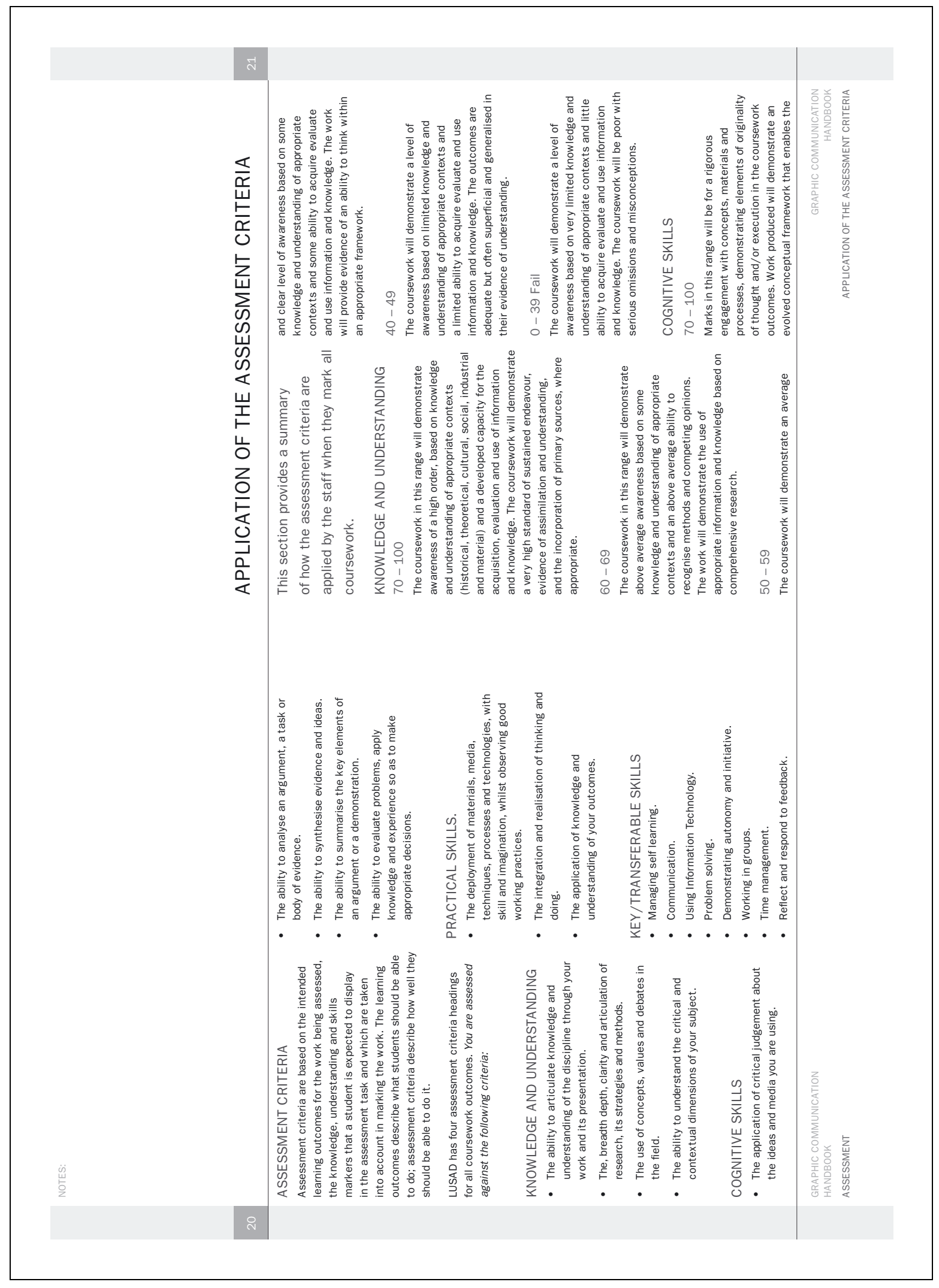




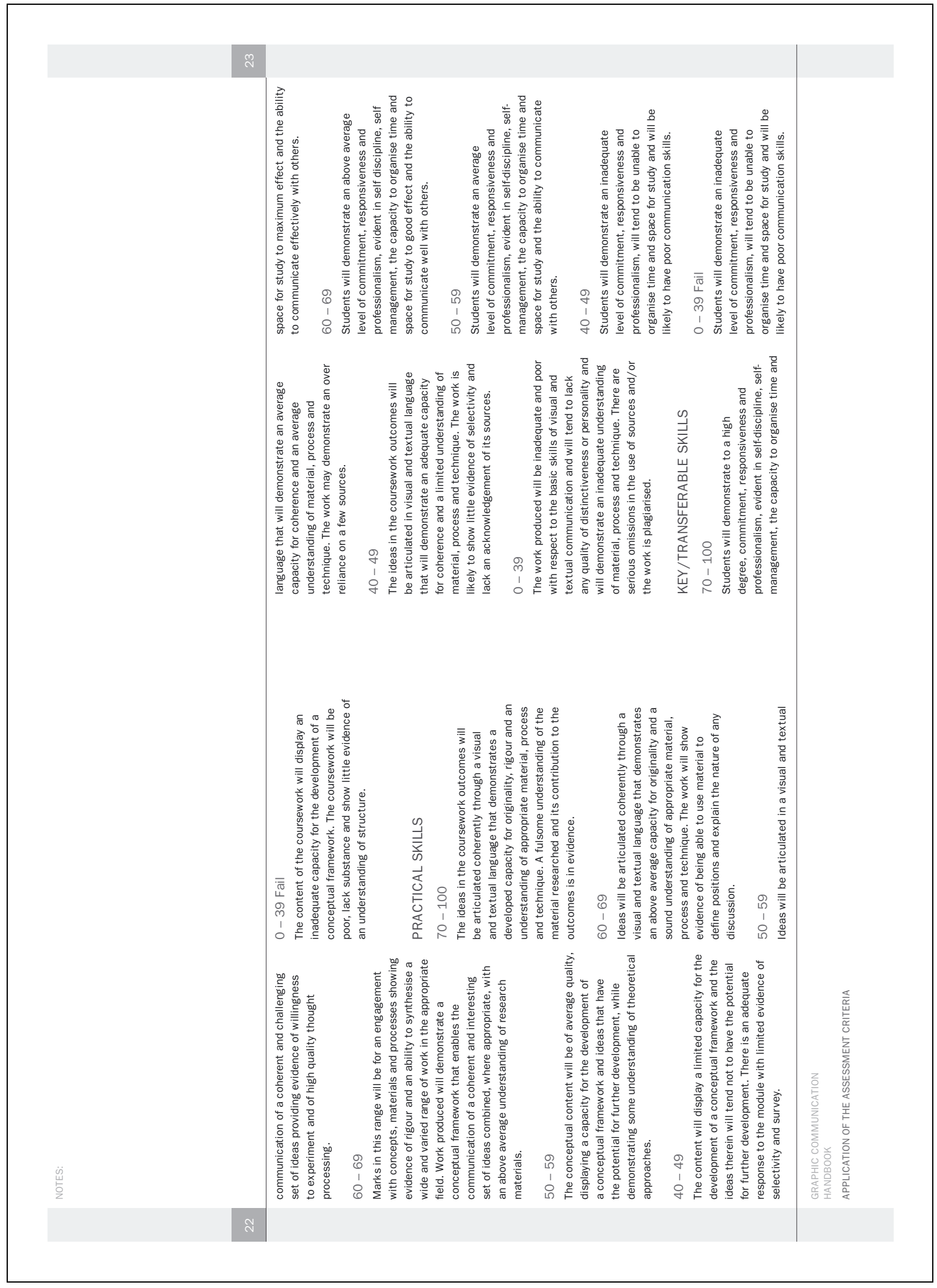

Figure 2: Previous formatting for assessment criteria and their application. [end page 83] [start page 84] 


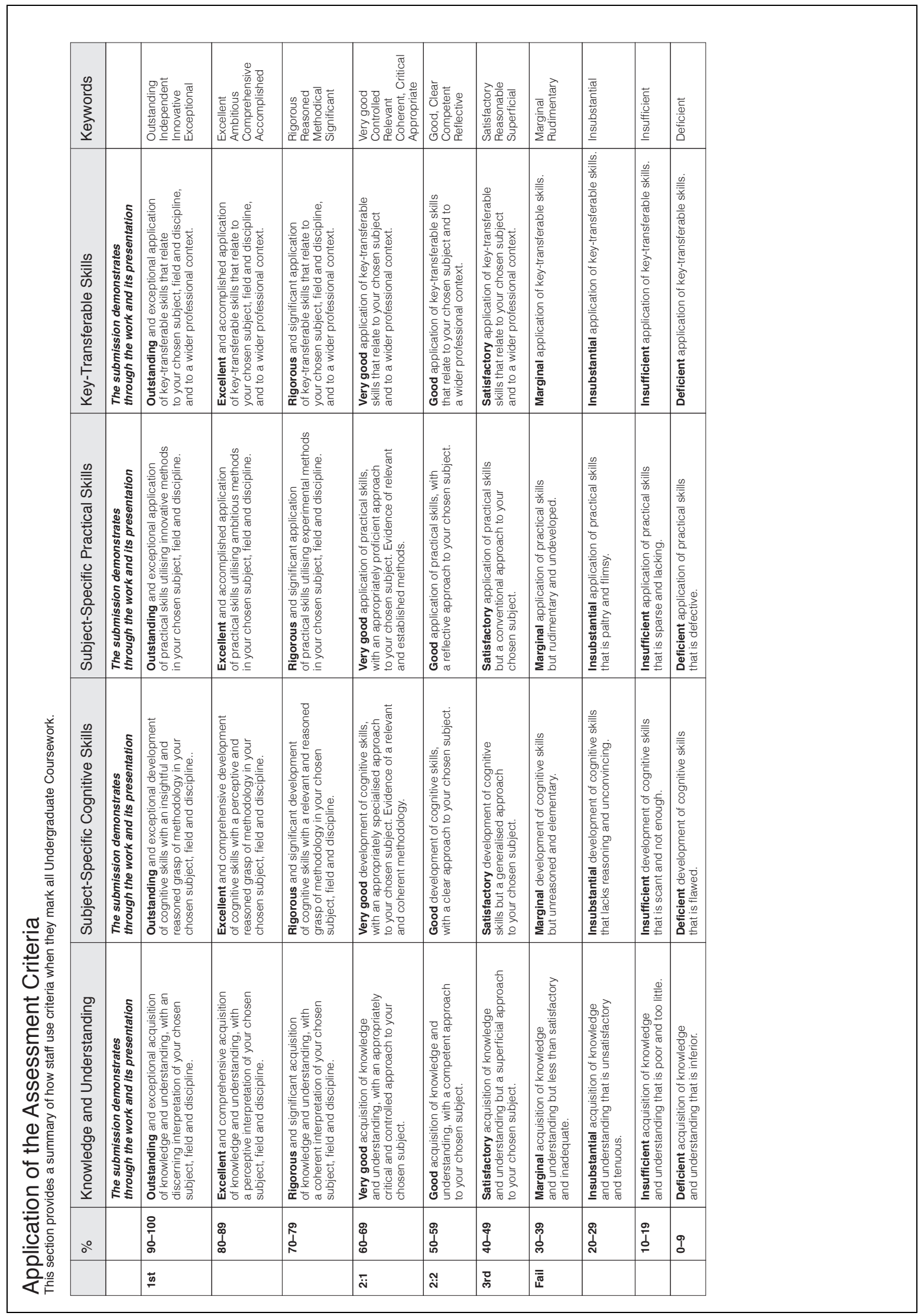

Figure 3: Revised assessment criteria for use in 2010-2011. [end page 84] [start page 85] 
Subject-specific practical skills

The submission demonstrates through the work and its presentation:

\begin{tabular}{|c|c|}
\hline & Student consultation \\
\hline $\begin{array}{l}1 \text { st } \\
90-100 \%\end{array}$ & $\begin{array}{l}\text { outstanding independent and } \\
\text { innovative practical skills in your } \\
\text { chosen subject, field and discipline. }\end{array}$ \\
\hline $\begin{array}{l}3 r d \\
40-49 \%\end{array}$ & $\begin{array}{l}\text { satisfactory awareness of art and } \\
\text { design practical skills, reasonable } \\
\text { familiarity with your chosen subject, } \\
\text { field and discipline, but is superficial } \\
\text { and generalised. }\end{array}$ \\
\hline $\begin{array}{l}\text { Fail } \\
0-9 \%\end{array}$ & $\begin{array}{l}\text { deficient art and design practical } \\
\text { skills that are unsatisfactory, } \\
\text { inadequate, and lacks reasoning. }\end{array}$ \\
\hline
\end{tabular}

\section{Approved version}

outstanding and exceptional application of practical skills utilising innovative methods in your chosen subject, field and discipline.

satisfactory application of practical skills but a conventional approach to your chosen subject.

deficient application of practical skills that is defective.

Table 6: Revisions to criteria after student consultation.

Implementation of the criteria took place in student handbooks for the 2010-2011 academic year. The first major assessment point happened at the end of Semester One in February 2011. Initial feedback from staff using the criteria, and others, is positive. The Disability and Additional Needs service at Loughborough University consider the revisions to be 'much clearer' and 'clarity... language and presentation' much better. Constructive feedback also points out that the matrix may be less successful if viewed only on-screen, and a linear approach may be more appropriate for this context. And, 'deficient' could be taken as an insult. The exercise has also stimulated interest from Loughborough University's Teaching Centre, where quality enhancement is located. They acknowledge how this kind of work in the School of the Arts, particularly within the context of a published student handbook, is impacting on wider university perspectives.

\section{Conclusion}

Across the art and design higher education sector variations exist in how institutions organize and articulate their assessment criteria. Whilst generally conforming to the sector norm in the United Kingdom - a first class degree is awarded for marks above $70 \%$, and a fail is less than $40 \%$ - the variety of ways institutions divide up the $0-100 \%$ range reveals irregular patterns of percentage grade banding and considerable difference in use of words to reflect levels [end page 85] [start page 86] of student achievement. This is potentially problematic if trying to establish consistent levels of achievement across the sector.

Attempts to be specific about levels of achievement appear to have focused in the past on the $35-80 \%$ range, and the matrix in Table 2 suggests some institutions believe it is possible to differentiate between as little as two - but most commonly three - percentage points. This has possibly been the result of most students achieving within this bracket, and therefore staff discussion about student achievement within this range has been most 
exercised. However, any criticism about the sparse use of marks outside this spectrum (high first or low fail) could be a result of inertia. One remedy to this is proposed here in the adoption of an even division of 10 per cent bands, conforming to example five in Table 1, to encourage use of the full spectrum of marks and the use of keywords, rather than 3 per cent increments to differentiate within a 10 per cent band.

Fail, satisfactory, good, very good and excellent might be thought of as a standard representation for five levels of achievement between fail and first. But at a time when more detailed written feedback to students is becoming the norm, team teaching is seen as beneficial to staff and students alike, specialist subjects seek interdisciplinary working, and institutional collaboration is encouraged, the need for a framework of common terms that represent levels of achievement is timely. Although some may reject this, close consideration should be given to the benefit it brings to students in being able to compare their own progress and ongoing achievement through their studies, as well as with their peers (as does happen). This process of consultation echoes what Wenger calls 'negotiability through engagement' which 'involves both the production of proposals for meaning and the adoption of these proposals' (1998: 202). Here, the production of assessment criteria is presented as a shared endeavour between staff and students that will continue to be negotiated between the key user groups.

However, student participation in the process of remodelling assessment criteria cannot be regarded here as substantial because of the sample size. That said, initial focus group results not only support the development process that is sensitive to student interpretation of keyword meaning but also keyword association in the context of a matrix. The decision to highlight key terms in bold at the beginning of each descriptor presented a useful navigational tool for staff and students who can then perhaps remember assessment bands on two levels: in the form of keywords and as descriptive text.

This work is ongoing, and forms part of the Loughborough University School of the Arts approach to defining a critical pedagogy, and desire for students to develop 'pedagogical intelligence' (O’Donovan et al. 2008: 213, citing Hutchings 2005). The exercise aligns with other working group activities that continue to review and develop summative written assessment feedback against intended learning outcomes, linked to negotiated formative feedback at interim stages in modules.

\section{Acknowledgements}

The authors wish to thank Dr Graham McLaren at Bath Spa University for his comments on an early draft of this article. Reviewer comments have also been welcome, specifically relating to research on assessment in a Business School context at Oxford Brookes University. [end page 86] [start page 87]

\section{References}

Biggs, M. and Buchler, D. (2008), 'Eight criteria for practice-based research in the creative and cultural industries', Art, Design \& Communication in Higher Education, 7: 1, pp. 5-18, doi: 10:1386/adche.7.1.5/1.

Blair, B. (2006), 'At the end of a huge crit in the summer, it was "crap" - I'd worked really hard but all she said was "fine" and I was gutted', Art, Design \& Communication in Higher Education, 5:2, pp. 83-95. 
Brown, G. (1997), Assessing Student Learning in Higher Education/George Brown with Joanna Bull and Malcolm Pendlebury, London: Routledge.

Bryman, A. (2008), Social Research Methods, Oxford: Oxford University Press.

Cowdroy, R. and Williams, A. (2006), 'Assessing creativity in the creative arts', Art, Design \& Communication in Higher Education, 5:2, pp. 97-117.

Denscombe, M. (2007), The Good Research Guide for Small Scale Research Projects, Maidenhead: Open University Press.

HEFCE (2011), 'REF 2014: Assessment framework and guidance on submissions', http://www.hefce.ac.uk/research/ref/pubs/2011/02_11/02_11.pdf. Accessed 13 October 2011.

Lave, J. and Wenger, E. (1999), 'Legitimate peripheral participation in communities of practice', in R. McCormick and C. Paechter, (eds.), Learning \& Knowledge, London: Paul Chapman Publishing in association with The Open University, pp. 21-35.

Malins, J. E. (2007), 'Assessment practices in the creative arts', The Higher Education Academy Art Design Media Subject Centre, www.adm.heacademy.ac.uk. Accessed on June 13, 2011.

Matthews, R. (2009), 'The use of peer assessment to improve student journalists' court reporting skills', The Higher Education Academy Art Design Media Subject Centre, www.adm.heacademy.ac.uk. Accessed on June 13, 2011.

O’Donovan, B., Price, M. and Rust, C. (2008), 'Developing student understanding of assessment standards: A nested hierarchy of approaches', Teaching in Higher Education, 13:2, pp. 205-17.

Orr, S. (2006), 'Assessment practices in art and design', Art, Design \& Communication in Higher Education, 5: 2, pp. 79-151, doi: 10.1386/adch.5.2.79_2.

(2010), 'Making marks: Assessment in art and design', in A. Crowe and D, Flint, (eds.), Networks, Brighton: The Higher Education Academy Art Design Media Subject Centre, pp. 9-13.

(2011), 'Artfully assessing artwork: an investigation into grading and feedback practices in art and design', in A. Crowe and D, Flint, (eds.), Networks, Brighton: The Higher Education Academy Art Design Media Subject Centre, pp. 53-54.

Price, M., Carroll, J., O’Donovan, B. and Rust, C. (2011), 'If I was going there I wouldn't start from here: A critical commentary on current assessment practice', Assessment \& Evaluation in Higher Education, 36:4, pp. 479-92. 
QAA (2006), Code of Practice for the Assurance of Academic Quality and Standards in Higher Education. Section 6: Assessment of Students - September 2006, Gloucester: The Quality Assurance Agency for Higher Education.

(2008), The Framework for Higher Education Qualifications in England, Wales and Northern Ireland, Gloucester: The Quality Assurance Agency for Higher Education.

Ramsden, P. (2003), Learning to Teach in Higher Education, London: Routledge Farmer.

[end page 87] [start page 88]

Rust, C., Price, M. and O’Donovan, B. (2003), 'Improving students' learning by developing their understanding of assessment criteria and processes', Assessment \& Evaluation in Higher Education, 28:2, pp. 147-64.

Sober, R. G. (2009), 'Team working and peer assessment: The assessment process as an aid to effective learning in creative group project work', The Higher Education Academy Art Design Media Subject Centre, www.adm.heacademy.ac.uk. Accessed on June 13, 2011.

Wareing, S. (2010), 'In praise of reification', in A Space for Assessment Symposium, Kingston University, 27-28 May.

Wenger, E. (1998), Communities of Practice: Learning, Meaning, and Identity, Cambridge: Cambridge University Press.

\section{Contributor details}

Dr Robert Harland is a lecturer in the School of the Arts, Loughborough University, where since 2011 he has been chair of the Learning and Teaching Committee. His disciplinary research and teaching focus on the relationship between typographic, graphic and urban design in the wider context of architecture and social science, but he also commits a third of his time to pedagogic research in art and design. He is a regular contributor to design research conferences and journals, and a member of the International Society of Typographic Designers Education Committee.

Contact: School of the Arts, Loughborough University, Loughborough, Leicestershire LE11 3TU, UK. E-mail: r.g.harland@lboro.ac.uk

Phil Sawdon was a senior lecturer in the School of the Arts, Loughborough University from 1987 to 2011. He was awarded an Honorary Fellowship for exceptional service in 2011. He chaired the School's Learning and Teaching Committee from 2005 to 2010 . He was a member of the Loughborough University Curriculum Sub-Committee from 2005 to 2010 as well as being a member of the Steering Group for the Loughborough University Employability Award. He is an artist, scholar and writer and co-editor of several journals and magazines including TRACEY (drawing and visualization) and stimulus respond.

Contact:School of the Arts, Loughborough University, Loughborough, Leicestershire LE11 3TU, UK. E-mail: pjsawdon@gmail.com 
Notes

${ }^{1}$ The School of the Arts is the formerly named School of Art and Design, since the 20102011 academic year.

2 'Contextual studies' here is used as a generic phrase to denote modules that produce written outcomes in the form of text analysis, essays or dissertation. This kind of module is named differently across the art and design sector. Some examples include Historical and Theoretical Studies, Critical and Historical Studies or Critical Studies.

${ }^{3}$ In addition to the authors of this article, the working group consisted of Pennie Alfrey, Tina Frank, Kerry Walton and Mark Wright. Although the School Learning and Teaching committee has student representation, they were omitted from the early working group due to the complexity of the task, and a desire to undertake a manageable process.

${ }^{4}$ Visual Communication is not a core subject in art and design. It applies to a wide set of academic subjects, fields and disciplines, but it is used by some in art and design as a generic term either to group separate undergraduate programmes, or as an undergraduate programme title. Recently it has been used by the School as a generic term to cluster two separate undergraduate degree programmes in Illustration and Graphic Communication. At the time of writing this situation is being reviewed and the two merged into a single programme structure.

${ }^{5}$ At Loughborough University School of the Arts, students must achieve a pass of 40 per cent in all modules (120 credits) before progression. This is not necessarily the case across Loughborough University, or the wider University sector where condonement might be utilized and a student can progress, for example, with 100 credits, having fulfilled additional requirements and achieved a module mark of a minimum 30 per cent. ${ }^{6}$ Further work on this may benefit from research into 'The law of comparative judgement' published by L. L. Thurstone in 1927. This is the basis of recent work on reliable assessment methods for minimizing marker subjectivity under the guise of research in 'Adaptive comparative judgement' at Goldsmiths, University of London, 2004-2009. 